ElementerIs: Jurnal Ilmiah Pendidikan Dasar Islam

Volume 1 Nomor 1 Mei 2019

e-ISSN: 2655-6324

\title{
PENDIDIKAN NILAI, BUDAYA DAN KARAKTER DALAM PEMBELAJARAN MATEMATIKA DASAR PADA SD/MI
}

\author{
Agus Setiawan ${ }^{1}$, Ika Ratih Sulistiani ${ }^{2}$ \\ ${ }^{1}$ Institut Agama Islam Ma'arif NU Metro Lampung, 2Universitas Islam Malang \\ 14905as@gmail.com, 2ika.ratih@unisma.ac.id
}

Diterima: 20 Mei 2019 I Direvisi: 23 Mei 2019 I Disetujui: 27 Mei 2019 (C) 2019 Pendidikan Guru Madrasah Ibtidaiyah Fakultas Agama Islam Universitas Islam Malang

\begin{abstract}
Value, culture and character education is an effort to improve the quality of the process and learning outcomes that lead to the formation of the character of students who are characterized by national culture. These cultural values and characters are the pride of the nation and make the nation known by other nations as a nation that has a distinctive Indonesian character. Education has a function in developing cultural values and past achievements into a proud element for the present and future life so that it becomes a strong foundation for national character. Value education, culture and national character are important points that must emerge in the learning process in the classroom. Integration of the three in the learning process, especially mathematics learning, is intended as a process of introducing values and culture, facilitating the acquisition of awareness of the importance of values and culture in the behavior of students through daily learning processes that take place both inside and outside the classroom on all math subjects. Thus, mathematics learning activities, in addition to making students master competencies (material taught in mathematics) are targeted, also to make students know, care, and internalize cultural and character values in everyday behavior.
\end{abstract}

Kata Kunci: Pendidikan Nilai, Budaya, Karakter, Pembelajaran Matematika.

\section{Pendahuluan}

Tujuan pendidikan nasional adalah mengembangkan potensi peserta didik agar menjadi manusia yang beriman dan bertakwa kepada Tuhan Yang Maha Esa, berakhlak mulia, sehat berilmu, cakap, kreatif, mandiri dan menjadi warga negara yang demokratis dan bertanggung jawab. Tujuan tersebut merupakan tujuan utama dalam proses penyelenggaraan pembelajaran yang menekankan pada pengembangan nilai, budaya, dan karakter bangsa. Membangun karakter bangsa pada generasi sekarang ini merupakan kegiatan yang mendesak dan bersifat sangat penting dilakukan (Sulistiani, 2019).

This work is licensed under Creative Commons Attribution Non Commercial 4.0 International License Available online on: http://riset.unisma.ac.id/index.php/je 
Matematika merupakan ilmu yang mengkaji obyek abstrak dan mengutamakan proses berpikir yang deduktif (Sulistiani, 2016). Pembelajaran matematika memerlukan berbagai macam keterampilan baik itu keterampilan yang berkaitan dengan kognitif, afektif maupun psikomotorik. Dengan adanya pembelajaran matematika diharapkan akan menambah kemampuan peserta didik dalam mengembangkan potensi dirinya. Namun kenyatannya, Banyak faktor yang menyebabkan merosotnya hasil belajar maupun karakter peserta didik saat ini.

Fenomena-fenomena permasalahan yang terjadi diantaranya siswa SD kepergok ramai-ramai sedang menghisap rokok elektrik di malang (Tribunnews, 2017), Polisi menangkap sejumlah anak SD yang akan tawuran dan membawa senjata tajam di Purwakarta (Tribun jabar, 2018), siswa SD meninggal usai berkelahi dengan teman sekelas di Garut (Detiknews, 2018), siswa SD menghamili siswi SMP di Tulungagung (Kompas, 2018). Berdasarkan kasus-kasus moral diatas, miris sekali ketika para pelakunya adalah siswa Sekolah Dasar (SD). Hal tersebut menunjukan bahwa karakter siswa tersebut mengalami degradasi yang sangat parah sehingga pendidikan nilai, karakter dan budaya harus segera di implementasikan ketiap-tiap satuan pendidikan Sekolah Dasar maupun Madrasahmadrasah Ibtidaiyah. Menurut Zuriah (2007), menganggap bahwa kemerosotan akhlak, moral, dan etika peserta didik disebabkan oleh gagalnya pendidikan agama di sekolah. Beberapa penelitian menunjukkan bahwa pembelajaran yang diintegrasikan dengan nilai-nilai agama, budaya dan karakter berimplikasi pada sikap positif siswa. Berdasarkan penelitian Setiawan (2016) menyimpulkan bahwa pembelajaran matematika dasar yang mengintegrasikan nilai - nilai keislaman dapat meningkatkan sikap religiusitas siswa. Fitriah, Syahrodi \& Muchyidin (2015) menunjukkan bahwa Model pembelajaran matematika berintegrasi keislaman dapat meningkatkan karakter demokrasi siswa.

\section{Metode Penelitian}

Pada artikel ini kami menggunakan pendekatan penelitian yang berupa Studi pustaka (Library Research). Studi pustaka merupakan suatu teknik yang digunakan dalam mengumpulkan informasi dan data memanfaatkan berbagai macam material dan sumber yang ada di perpustakaan diantaranya dokumen, buku, majalah, kisah-kisah sejarah, dsb (Mardalis:1999). Studi pustaka juga dapat menganalisis macam-macam referensi serta hasil penelitian sejenis sebelumnya yang dapat digunakan untuk mendapatkan landasan teori mengenai berbagai masalah yang akan diteliti (Sarwono:2006). Selain itu juga, Studi pustaka 
merupakan teknik pengumpulan data dengan penelaahan terhadap buku, literatur, catatan, serta berbagai laporan yang berkaitan dengan masalah yang ingin dipecahkan (Nazir:1988). Sedangkan menurut ahli lain studi pustaka berkaitan dengan budaya, nilai dan norma yang berkembang pada situasi sosial yang diteliti (Sugiyono:2012).

\section{Hasil dan Pembahasan}

\section{Fungsi dan Tujuan Pendidikan Budaya dan Karakter Bangsa}

Menurut Badan Penelitian dan Pengembangan Pusat Kurikulum (2010), Fungsi pendidikan Budaya dan Karakter bangsa diantaranya adalah: 1) Pengembangan: mengembangakan potensi peserta didik agar memiliki sikap dan perilaku yang mencerminkan budaya dan karakter bangsa 2) Perbaikan: memperkuat tujuan pendidikan nasional dalam ranah pengembangan pendidikan; dan 3) Penyaring: menyaring berbagai macam unsur budaya baik itu budaya sendiri maupun budaya asing yang tidak sesuai dengan nilai - nilai karakter yang bermartabat.

Sedangkan tujuan pendidikan budaya dan karakter bangsa adalah: 1) mengembangkan potensi sebagai manusia dan warganegara yang memiliki nilai nilai budaya dan karakter; 2) mengembangkan kebiasaan dan perilaku yang terpuji dan sejalan dengan nilai-nilai universal dan tradisi budaya bangsa yang religius; 3) menanamkan jiwa kepemimpinan dan tanggung jawab sebagai generasi penerus bangsa; 4) mengembangkan kemampuan menjadi manusia yang mandiri, kreatif, berwawasan kebangsaan; dan 5) mengembangkan lingkungan kehidupan sekolah sebagai lingkungan belajar yang aman, jujur, penuh kreativitas dan persahabatan, serta dengan rasa kebangsaan yang tinggi dan penuh kekuatan (dignity).

\section{Nilai-nilai dalam Pendidikan Budaya dan Karakter Bangsa}

Menurut Badan Penelitian dan Pengembangan Pusat Kurikulum (2010), Nilai - nilai pendidikan budaya dan karakter yang akan dikembangakan berakar dari beberapa hal, diantaranya:

1. Agama: kehidupan kenegaraan di masyarakat perlu didasari pada nilai - nilai agama. Nilai - nilai agama ini lah yang menjadi fondasi dalam membentuk nilai - nilai pendidikan budaya dan karakter. Kehidupan masyarakat dalam berbangsa dan bernegara selalu di dasari pada ajaran dan kepercayaannya.

2. Pancasila: NKRI berdiri dan ditegakkan atas dasar prinsip-prinsip kehidupan berkebangsaan dan kenegaraan yang disebut Pancasila. Pancasila tercantum dalam Pembukaan UUD 1945 dan penjabaran lebih lanjut pada 
pasal - pasal dalam UUD 1945 tersebut. Nilai-nilai yang tercantum dalam Pancasila menjadi nilai yang mendasari dalam setiap aspek kehidupan bangsa dan negara ini. Tujuan penting adanya Pendidikan budaya dan karakter bangsa adalah mempersiapkan peserta didik menjadi warga negara yang menjadi lebih baik yang memiliki kemampuan, kemauan, dan menerapkan nilai - nilai Pancasila dalam setiap kehidupan bermasyarakat dan bernegara.

3. Budaya: Nilai - nilai budaya merupakan kebenaran yang ada dalam masyarakat. Nilai ini menjadi dasar hidup manuasia dalam hidup bermasyarakat. Nilai-nilai budaya menjadikan konsep dan makna komunikasi dalam suatu masyarakat berjalan dengan selaras dan seirama. Dengan demikian posisi nilai budaya inilah yang harus di jaga keharmonisannya dalam menerapkan pendidikan budaya dan karakter bangsa.

4. Tujuan Pendidikan Nasional: untuk menghasilkan kualitas manusia indonesia yang sesuai dengan nilai-nilai karakter dan bangsa indonesia. Maka perlu adanya rumusan pengembangan dalam berbagai aspek kehidupan diantaranya kehidupan dalam pendidikan. Pemerintah sudah mengembangkan berbagai kualitas dalam dunia seperti peningkatan kualitas satuan pendidikan dalam berbagai jenjang dan jalur pendidikan. Dalam rumusan tujuan pendidikan nasional terkandung berbagai nilai kemanusiaan yang harus dimiliki oleh warga negara indonesi. Tujuan pendidikan nasional menjadi sumber yang paling operasional dalam mengembangkan pendidikan budaya dan karakter bangsa.

\section{Pendidikan Nilai, Karakter Dan Budaya dalam Pembelajaran Matematika}

Pengembangan budaya dan karakter bangsa tidak akan mungkin akan dimasukkan sebagai unsur yang terpisah dalam pokok bahasan tetapi harus melalui proses integrasi ke dalam mata pelajaran, pengembangan diri, dan budaya sekolah. Oleh karena itu, semua elemen pendidikan ( guru dan pihak -pihak sekolah) perlu mengintegrasikan nilai-nilai tersebut dalam proses pembelajaran kususnya matematika.

1. Nilai kejujuran pada penjumlahan

Matematika mengajarkan prisndip kejujuran. Dimana ketika kita melakukan operasi (missal penjumlahan) dalam matematika dan tidak sesuai dengan sifat-sifat tau teorema-teorema yang berlaku tentunya pekerjaan kita akan salah. Contoh: dalam aturan penjumlahan terdapat beberapa sifat-sifat penjumlahan salah satunya yaitu komutatif $(a+b=b+a)$

Misal kita ambil dua bilangan yaitu bilangan $\mathrm{a}=2$, dan bilangan $\mathrm{b}=4$;

Ruas kiri; $a+b=2+4=6$ 
Ruas kanan; $\mathrm{b}+\mathrm{a}=4+2=6$

Hasil penjumlahan sama yaitu 6, jadi berlaku sifat komutatif

2. Nilai semangat bersedekah pada perkalian

Dalam Surat Al-Baqarah ayat 261 yang artinya. "perumpamaan (nafkah yang dikeluarkan oleh) orang-orang yang menafkahkan hartanya dijalan Alloh adalah serupa dengan sebutir benih yang menumbuhkan 7 bulir, pada tiap-tiap bulir serratus biji. Alloh melipatgandakan (ganjaran) bagi siapa yang Dia kehendaki dan Alloh maha luas (karunia-Nya) lagi maha mengetahui".

Berdasarkan Surat tersebut dapat kita formulasikan pahala bagi orang yang bersedekah dijalan Alloh yaitu 1 x 7 x 100. Jika bersedekah Rp. 1000, maka akan dilipatgandakan menjadi $1000 \times 7 \times 100=700.000$. Berdasarkan hal tersebut dapat kita tanamkan kepada siswa untuk selalu bersedekan ketika mempunyai rezeki lebih.

3. Nilai kesederhanaan pada pembagian pecahan

Dalam matematika nilai kesederhanaan dapat disisipkan pada pembagian pecahan karna pada materi pecahan selagi pecahan tersebut masih bisa disederhanakan menjadi lebih kecil maka dapat diambil yang paling sederhana. Contoh

Sederhakan pecahan $\frac{4}{8}$

Jawab: pecahan tersebut dapat disederhanakan menjadi:

$\frac{4}{8}($ pembilang dan penyebut dibagi 2$)=\frac{2}{4}$

$\frac{2}{4}($ pembilang dan penyebut dibagi 2$)=\frac{1}{2}$

Jadi, bentuk sederhana dari $\frac{4}{8}$ yaitu $\frac{1}{2}$

4. Nilai adil pada pembagian

Secara bahasa adil diartikan sama besar. Sedangkan dalam pembagian, membagi suatu bilangan akan menghasilkan suatu bilangan yang sama besar nilainya.

Contoh: adi mempunyai enam buah jeruk yang akan dibagikan kepada tiga temannya yaitu ani, ria dan ina, berapakah masing-masing bagian buah jeruk yang didapat?

Dalam hal ini ada beberapa kemungkinan jawaban jika tidak menggunakan prinsip pembagian. Bisa saja ani mendapat satu buah, ria mendapat 3 buah dan ina mendapat 2 buah, hasil ini benar akan tetapi apakah adil?

Jika menggunakan pembagian yaitu:

$\frac{6}{3}=2$ 
Jadi, setiap teman akan sama-sama mendapat dua buah jeruk.

5. Nilai budaya melalui Etnomatematika

D'Ambrosio adalah orang yang pertamakali memperkenalkan etnomatematika pada tahun 1977. Etnomatematika menurut para ahli yaitu: Studi dan presentasi ide-ide matematika masyarakat tradisional. (Ascher, 1991). Matematika merupakan praktik budaya. (Presmeg, 1996). Ethnomathematics mengacu pada segala bentuk pengetahuan budaya atau karakteristik aktivitas sosial dari kelompok sosial dan / atau budaya, yang dapat dikenali oleh kelompok lain seperti antropolog, tetapi tidak harus oleh kelompok asal, sebagai pengetahuan matematika atau aktivitas matematika. (Pompeu, 1994). Penelitian Indriani (2016) menunjukkan bahwa bahwa motif tenun kain tapis Sanggar Rahayuterdiri dari motif geometri, manusia, binatang, dan motif tumbuh-tumbuhan,sedangkan Siger Lampung memiliki unsur matematika didalamnya yakni segitiga. Zaenuri dan Dwidayati (2017), etnomatematik dalam budaya masyarakat di wilayah pesisir utara Pulau Jawa adalah dalam bentuk: (a) bangunan budaya (Menara Kudus), (b) bangunan non-budaya, makanan tradisional dan (c) batik motif, dan berbagai bentuk ethnomathematics dalam komunitas yang dipelajari berhubungan dengan konsep matematika yang mereka dapat diintegrasikan ke dalam pembelajaran-pengajaran matematika kegiatan baik di tingkat dasar dan menengah.

\section{Simpulan}

Pembelajaran tidak hanya memberikan manfaat kepada siswa baik secara kognitif, afektif, maupun psikomotik, tetapi makna yang lebih khusus bahwa pembelajaran itu sendiri dapat memberikan nilai - nilai yang bisa digunakan untuk membentuk karakter peserta didik menjadi manusia yang lebih baik. Pendidikan nilai, budaya dan karakter dalam pembelajaran matematika dasar sangat penting dalam rangka memenuhi kebutuhan peserta didik khusunya pada jenjang Sekolah Dasar. Kebutuhan peserta didik tidak hanya berhubungan dengan memahami konsep matematika tetapi juga kebutuhan akan pentingnya nilai, karakter serta dikenalkan dan mencintai budaya sejak dini.

\section{Daftar Rujukan}

Ascher, M. (1991). Ethnomathematics: A multicultural view of mathematical ideas. New York: Chapman and Hall.

Badan Penelitian dan Pengembangan Pusat Kurikulum. 2010. Pengembangan Pendidikan Budaya dan Karakter Bangsa. Jakarta: Kemendiknas. 
Fitriah, N., Syahrodi, M dan Muchyidin, A. (2015). Implementasi model pembelajaran matematika terintegrasi islam dalam meningkatkan sikap demokratis siswa. Jurnal EduMa vol 4, no 2

Indriani, P. (2016). Implementasi Etnomatematika Berbasis Budaya Lokal dalam Pembelajaran Matematika pada Jenjang sekolah Dasar. IAIN Raden Intan Lampung.

Mardalis. (1999). Metode Penelitian Suatu Pendekatan Proposal. Jakarta : Bumi Aksara.

Nazir, M. (1988). Metode Penelitian. Jakarta: Ghalia Indonesia.

Pompeu, G. (1994). Newsletter of the International Study Group on Ethnomathematics, 9(2), 3.

Presmeg, N. C. (1996). Ethnomathematics and academic mathematics: The didactic interface. Paper presented in Working Group 21, The Teaching of Mathematics

in

Different Cultures, Eighth International Congress on Mathematical

Education, Seville, Spain.

Sarwono. (2006). Metode Penelitian Kuantitatif dan Kualitatif. Yogyakarta:Graha Ilmu

Setiawan, A. (2019, April 15). Pembelajaran Matematika Dasar Berintegrasi Keislaman Untuk Meningkatkan Sikap Religiusitas Siswa. Retrieved from osf.io/nb5v7

Sugiyono. (2012). Metode Penelitian Kuantitatif, Kualitatif dan R\&D. Bandung: Penerbit Alfabeta.

Sulistiani, I. R. (2016). Pembelajaran Matematika Materi Perkalian dengan Menggunakan Media Benda Konkret (MANIK -MANIK DAN SEDOTAN) Untuk Meningkatkan Hasil BelajarR Siswa Kelas 2 SD DINOYO 1 MALANG. Vicratina : Jurnal Pendidikan Islam, 1(2), 22-23.

Sulistiani, I. R. (2019). Literasi Matematika dalam Pendidikan Karakter Bangsa. In A. Sa'dullah (Ed.), Pendidikan Karakter Kebangsaan Teori dan Praktik (1st ed., pp. 222-234). Malang: Intelegensia Media.

Zaenuri dan Dwidayati, N. (2017). Exploring ethnomathematics in Central Java. International Conference on Mathematics, Science and Education, IOP Conf. Series: Journal of Physics.

Zuriah, N. (2007). Pendidikan Moral dan budi Pekerti dalam perspektif Perubahan. Jakarta: Bumi Aksara. 
Agus Setiawan, Ika Ratih Sulistiani

https://news.detik.com/berita-jawa-barat/d-4130044/bocah-kelas-6-sd-di-garuttewas-berkelahi-dengan-teman-sekelas

http://www.tribunnews.com/regional/2017/09/12/geger-bocah-sd-di-malangkepergok-ramai-ramai-hisap-rokok-elektrik 